\title{
An Analysis on Correlation Between Intercultural Sensitivity and English Proficiency of English Majors in China
}

\author{
Yuhuan Wang \\ College of Foreign Languages \\ Qingdao Agricultural University \\ Qingdao, China \\ wangyuhuanalice@163.com
}

\author{
Fang Huang \\ College of Foreign Languages \\ Qingdao Agricultural University \\ Qingdao, China \\ huang311fang@163.com
}

\begin{abstract}
The study investigated the correlation between intercultural sensitivity and English proficiency of 258 Englishmajor juniors from three universities in China. The study employed the Intercultural Sensitivity Scale explored by Chen and Starosta (2000) to measure participants' intercultural sensitivity in five aspects. The Correlation and One-Way ANOVA are used to analyze the data. Results showed that English proficiency has some positive effects on English learners' intercultural sensitivity. It showed participants with higher TEM-4 scores acquired the higher intercultural sensitivity than those with lower TEM-4 scores.
\end{abstract}

Keywords- intercultural sensitivity; intercultural sensitivity scale; English-major students; English proficiency; quantitative study;

\section{INTRODUCTION}

With a fast development in transportation, communication, trading and other fields in the multicultural and globalizing society, the importance of acquiring intercultural communication competence (ICC) has been well recognized. In the past decades, much attention has been paid to the study of ICC. Intercultural scholars have attempted to figure out what ICC is and what the elements of ICC are (e.g., Gudykunst, \& Wiseman, 1977; Chen, 1997, 2000; Lustig \& Koester, 2007; Spitzberg \& Changnon, 2009). They argued that ICC refers to the ability to communicate appropriately and effectively with people of different cultural backgrounds. They argued that ICC consisted of four dimensions: personal attributes, communication skills, psychological adaptation and cultural awareness. Chen (1996) went one step further and pointed out that ICC could be examined from three perspectives: (1) cognitive-intercultural awareness; (2) affective-intercultural sensitivity; and (3) behavioral—intercultural adroitness.

Intercultural sensitivity is the core factor to connect intercultural awareness with intercultural skills. The academic attention to the essence of intercultural sensitivity has been paid home and abroad. This thesis focuses on assessing the intercultural sensitivity (ICS) of Chinese college English majors. This investigation is expected to provide first-hand data about the ICS level of English majors in universities of China and find out whether there exist positive correlation between English proficiency and ICS, which can shed light on the designing of curriculum, syllabus, teaching materials for developing students' intercultural communication competence.

\section{LITERATURE REVIEW}

Intercultural sensitivity is a well-acknowledged component of intercultural communication competence. Bronfenbrener (1958) defined the concept of interpersonal sensitivity as the ability to distinguish how others differ in the behavior, perceptions or feelings. According to Bennett (1993), intercultural sensitivity is the construction of reality as increasingly capable of accommodating cultural difference that constitutes intercultural development. The affective perspective of ICC is represented by intercultural sensitivity that refers to the subjects ' "active desire to motivate them to understand, appreciate, and accept differences among cultures” (Chen \& Starosta, 1998).

Bennett (1986) forwarded the conceptual framework of intercultural sensitivity. He argued that intercultural sensitivity is composed of six distinct personal characteristics: self-esteem, self-monitoring, empathy, open-mindedness, interaction involvement and suspending judgment. Bennett explored the Development Model of Intercultural Sensitivity and Intercultural Development Inventory in 1998. The latter has been recognized as a good measurement for testing intercultural sensitivity. Chen advanced Bennett's (1986) six distinct personal characteristics in three dimensions and explored an intercultural sensitivity scale (ISS) by making factor analysis based on the above six characteristics. The scale has been accepted as the most valid and acceptable measurement at present.

Domestic research on intercultural sensitivity began in China in 1980s. Retrieval on intercultural sensitivity study from 1994 to 2009 was made on Chinese Net CNKI, but found only nineteen articles published entitled intercultural sensitivity. Most of the articles made descriptive analysis on intercultural sensitivity. Few scholars such as Peng Shiyong (2005, 2007), Zhou Xingying \& Peng Xuemin (2007) has done quantitative analysis on the intercultural sensitivity. Peng Shiyong (2007) made comparison between English majors and non-English majors in intercultural sensitivity. Peng Xuemin (2007) did research on the influence of cultural study on intercultural 
sensitivity. However, no quantitative research has been done on the correlation between English proficiency and intercultural sensitivity on college students' level in China.

This study adopted an intercultural sensitivity scale (ISS) explored by Chen \& Starosta (2000) by using SPSS17.0 to make the assessment in the affective perspective of ICC. In specific, the study aims to probe into the following questions: 1 ) how the intercultural sensitivity correlates to the TEM-4 and 2) to what extent the students from the different universities differ in terms of five elements of intercultural sensitivity. The aim of the study is to explore whether there is direct effect of English proficiency on intercultural sensitivity. If there is some correlation, what should be done to enhance English learners' intercultural sensitivity so as to strengthen their intercultural communication competence in China?

\section{METHODOLOGY}

\section{A. Participants}

The participants were English-major juniors from three universities, Shandong Normal University (SNU), Lu Dong University (LDU), and Qingdao Agricultural University (QAU) in China. We chose the three universities as the source for our sampling to obtain a representative sample of the characteristics of English major juniors across China. 280 participants from the three universities participated in the study. They completed the 24-item English version of ISS in about 12 minutes in Class. Among the total 258 valid questionnaires, 107 were from SNU, 83 were from LDU and were 68 from QAU.

TABLE I. DESCRIPTIVES OF TEM-4 SCORES

\begin{tabular}{|c|c|c|c|c|c|c|}
\hline & N & Mean & S.D. & S.E. & Min & Max \\
\hline QAU & 68 & 63.4632 & 6.74886 & .81842 & 50.00 & 79.00 \\
LDU & 83 & 64.1265 & 5.90672 & .64835 & 50.00 & 77.00 \\
SDNU & 107 & 68.8411 & 7.12576 & .68887 & 57.00 & 88.00 \\
Total & 258 & 65.9070 & 7.08076 & .44083 & 50.00 & 88.00 \\
\hline
\end{tabular}

TABLE II. DIFFERENCE OF TEM-4 SCORES BY ANOVA

\begin{tabular}{|l|l|l|l|l|l|}
\hline & Sum of Squares & df & $\begin{array}{l}\text { Mean } \\
\text { Square }\end{array}$ & F & Sig. \\
\hline Between & 1590.389 & 2 & 795.194 & 17.95 & .000 \\
groups & 11294.879 & 25 & 44.294 & 3 & \\
Within & 12885.267 & 5 & & & \\
groups & & 25 & & & \\
Total & & 7 & & & \\
\hline
\end{tabular}

Table I shows that the mean of all the 258 participants' English proficiency in TEM-4 is 65.9070, which is higher than the mean of QAU (63.4632) and LDU (64.1265), but lower than the mean of SDNU (68.8411). One-Way ANOVA is used to test whether there is statistically significant difference among students from the three universities. Table II indicates that there are statistically significant differences $(F=17.953$, $p$ $=.000)$ in English proficiency among students who are from QAU, LDU and SDNU.

\section{B. Instruments}

The study uses the Intercultural Sensitivity Scale (ISS) designed by Chen and Starosta (2000). The ISS consists of 24 items that represent the empiral indicators of the six components for the measurement of intercultural sensitivity in five aspects. Questions 1, 11, 13, 21, 22, 23,24 were designed to target participants' interaction engagement. Questions 3, 4, 5, 6, 10 were concerned about participants' interaction confidence. Questions 14, 17, 19 were intended to probe into participants' interaction attentiveness. Questions 9, 12, 15 were to focus on the study of interaction enjoyment. Questions 2, 7, 8, 16, 18, 20 were to investigate participants' respect for cultural difference.

There are two parts in the questionnaire: personal information and questions. The personal information consists of name, gender, university, hometown and English level. The study defines nation-wide Tests for English majors at Band 4 (TEM4) at tertiary level as a standard to evaluate the participants' English proficiency.

The second part is composed of 24 questions that touch upon five aspects of measuring intercultural sensitivity. This research used the statistic tool of SPSS 17.0 to sort out and analyze the data in the questionnaires. A five-point Likert scale was used to make response to each item: $5=$ strongly agree, 4=agree, 3=uncertain, 2=disagree, and 1=strongly disagree.

\section{The administration of instruments}

On the first step, we chose 12 English-major juniors at QAU to answer the questionnaire at a limited time for a trial. The participants' responses were analyzed for testing the reliability of the questionnaire by SPSS 17.0. And we found the questionnaire was valid and acceptable for our research.

Secondly, teachers at SNU, LU and QAU distributed the papers in their classes. In order to collect complementary evidence for the study, the teachers explained how to do the questionnaires and stressed the significance of the research briefly to the participants. They observed students do questionnaires carefully within 12 minutes in class.

Thirdly, we put in the collected valid data into SPSS software. Before we calculated the results, the options to 9 items (Q2, Q4, Q7, Q9 Q12, Q15, Q18, Q20, Q22) were recoded, that is to say, the original response five point scales of 5. Strongly agree, 4. Agree, 3. Uncertain, 2. Disagree, 1. Strongly disagree were recoded/transformed into $5=$ strongly disagree, 4=disagree, 3=uncertain, 2=agree, 1=strongly agree so that the values would be reasonably correlated with the scores.

In order to make an evidence to answer the questions, the Correlation and One-Way ANOVA are used to analyze the data provided by the Questionnaire.

\section{RESEARCH FINDINGS}

In order to investigate 1) how the intercultural sensitivity correlate to the TEM-4 and 2) to what extent the students from the different universities differ in terms of intercultural 
sensitivity, the Correlation is used to explore the former and ANOVA the latter. Below is the quantitative analysis of the 5 aspects of the intercultural sensitivity based on the data provided by participants in the three universities.

\section{A. In the aspect of engagement}

To calculate how the aspect of engagement of intercultural sensitivity $(Q 1,11,13,21,22,23,24)$ correlates with TEM-4 scores, the Correlation is used for this purpose. To put the items for investigating the engagement into the Correlation Procedures (SPSS 17.0), we got results as Table III shows that only Q1 is significantly correlated with TEM-4 scores $(\mathrm{r}=.224)$ at the level of $\mathrm{p}=.000$, while the rest items such as Q11 and Q24 have no significant correlation with TEM-4 scores. This signifies that the more those who "enjoy interacting with people from different cultures" the more they do better in their study or that the students with higher English proficiency are more willing to enjoy interacting with people from different cultures.

TABLE III. CORRELATION BETWEEN THE ENGAGEMENT AND

\begin{tabular}{|l|l|l|c|c|}
\hline \multicolumn{5}{|c|}{ TEM-4 SCORE } \\
\hline TEM-4 score & $\begin{array}{l}\text { Spearman's } \\
\text { rho }\end{array}$ & $.224^{* *}$ & -.017 & .094 \\
\hline & Sig. (2-tailed) & .000 & .790 & .133 \\
\hline & N & 258 & 258 & 258 \\
\hline
\end{tabular}

To calculate to what extent the students from the different universities differ in terms of the engagement in intercultural sensitivity, One-Way ANOVA is used to provide Table IV as below. Table IV below shows that participants in the three universities have significant difference in Q1 ( I enjoy interacting with people from different cultures) ( $\mathrm{p}=.000), \mathrm{Q} 24$ (I have a feeling of enjoyment toward difference between my culturally-distinct counterpart and me) (p =.012), and Q11 (I tend to wait before forming an impression of culturally-distinct counterparts) ( $\mathrm{p}=.094$, marginally significant). This generally conforms to the above correlation results that the more they behave as the items reflect the more they achieve.

TABLE IV. DIFFERENCE AMONG THE THREE UNIVERSITIES IN ENGAGEMENT BY ANOVA

\begin{tabular}{|c|c|c|c|c|}
\hline & $\mathbf{N}$ & Mean & Std. Deviation & Sig. \\
\hline Q1 QAU & 68 & 3.78 & .844 & .000 \\
LDU & 83 & 4.06 & .687 & \\
SDNU & 107 & 4.28 & .579 & \\
\hline Q11 QAU & 68 & 3.47 & .701 & .094 \\
LDU & 83 & 3.31 & .795 & \\
SDNU & 107 & 3.21 & .753 & \\
\hline Q24 QAU & 68 & 3.63 & .751 & .012 \\
LDU & 83 & 3.87 & .694 & \\
SDNU & 107 & 3.93 & .527 & \\
\hline
\end{tabular}

\section{B. In the aspect of rescpect for cultural differences}

Table V shows that Q2, Q7 and Q20 are significantly correlated with TEM-4 scores at the level of respective $\mathrm{p}=$. $011, \mathrm{p}=.033, \mathrm{p}=.011$, but the more important is the negative correlation. This may suggest that the more those who "think people from other cultures are narrow-minded”, “don't like to be with people from different cultures", and "think my culture is better than other cultures", the less they achieve in their English study.

TABLE V. CORRELATIONS BETWEEN RESPECT FOR CULTURAL DIFFERENCE WITH TEM-4 SCORES

\begin{tabular}{|c|c|c|c|c|c|c|}
\hline & & Q2 & Q7 & Q8 & Q18 & Q20 \\
\hline $\begin{array}{l}\text { TEM- } \\
\text { score }\end{array}$ & $\begin{array}{c}\text { Spearman's } \\
\text { rho }\end{array}$ & $-.157 *$ & $-.132 *$ & -.104 & -.029 & $-.211^{* *}$ \\
\hline & $\begin{array}{c}\text { Sig. (2- } \\
\text { tailed) }\end{array}$ & .011 & .033 & .096 & .646 & .011 \\
\hline & N & 258 & 258 & 258 & 258 & 258 \\
\hline
\end{tabular}

To calculate to what extent the students from the different universities differ in terms of the respect for culture differences in intercultural sensitivity, One-Way ANOVA is used. Table VI shows that participants in the three universities have significant difference in Q2 (I think people from other cultures are narrow-minded.) ( $\mathrm{p}=.030)$, Q7 (I don't like to be with people from different cultures) $(\mathrm{p}=.015)$ and Q20 (I think my culture is better than other cultures) $(\mathrm{p}=.079)$. This may confirm the result of the above correlation that the more they have these sensitivities the less they achieve.

TABLE VI. THE DIFFERENCES AMONG THE THREE UNIVERSITIES IN RESPECT FOR CULTURAL DIFFERENCES BY ANOVA

\begin{tabular}{|l|l|l|l|}
\hline & \multicolumn{1}{|c|}{$\mathbf{N}$} & \multicolumn{1}{|c|}{ Mean } & Sig. \\
\hline Q2 QAU & 68 & 1.97 & .030 \\
LDU & 83 & 1.87 & \\
SDNU & 107 & 1.71 & \\
\hline Q7 QAU & 68 & 2.18 & .015 \\
LDU & 83 & 1.94 & \\
SDNU & 107 & 1.87 & \\
\hline Q8 QAU & 68 & 4.50 & .188 \\
LDU & 83 & 4.59 & \\
SDNU & 107 & 4.43 & \\
\hline Q18 QAU & 68 & 1.97 & .463 \\
LDU & 83 & 1.86 & \\
SDNU & 107 & 1.86 & \\
\hline Q20 QAU & 68 & 2.56 & .079 \\
LDU & 83 & 2.45 & \\
SDNU & 107 & 2.27 & \\
\hline
\end{tabular}

C. In the aspect of confidence

The same correlation statistical procedures are used to provide Table VII below which indicates that no statistically significant correlation between this confidence in intercultural sensitivity and TEM-4 scores. This may suggest that those 
with the characteristics as Q3, Q4, Q5, Q6, Q10 show have no significant positive or negative correlations with TEM-4 score.

TABLE VII. CORRELATIONS BETWEEN CONFIDENCE WITH CET-4 SCORES

\begin{tabular}{|c|c|c|c|c|}
\hline & & $\mathbf{Q 4}$ & $\mathbf{Q 5}$ & $\mathbf{Q 1 0}$ \\
\hline $\begin{array}{c}\text { TEM-4 } \\
\text { score }\end{array}$ & Spearman's rho & -.038 & -.044 & .036 \\
\hline & Sig. (2-tailed) & .542 & .478 & .562 \\
\hline & $\mathrm{N}$ & 258 & 258 & 258 \\
\hline
\end{tabular}

Table VIII below shows that students in the three universities have no significant difference in Q3, Q4, Q5, Q6, and Q10. This may also confirm to the result of the above correlation that those students with the characteristics as Q3, Q4, Q5, Q6, Q10 reflect have no significant effect on TEM-4 score.

TABLE VIII. THE DIFFERENCE AMONG THE THREE UNIVERSITIES IN CONFIDENCE BY ANOVA

\begin{tabular}{|c|c|c|c|}
\hline & $\mathbf{N}$ & Mean & Sig. \\
\hline Q3 QAU & 68 & 3.43 & .522 \\
LDU & 83 & 3.31 & \\
SDNU & 107 & 3.42 & \\
\hline Q4 QAU & 68 & 2.87 & .235 \\
LDU & 83 & 2.61 & \\
SDNU & 107 & 2.70 & \\
\hline Q5 QAU & 68 & 2.74 & .291 \\
LDU & 83 & 2.93 & \\
SDNU & 107 & 2.82 & \\
\hline Q6 QAU & 68 & 3.34 & .860 \\
LDU & 83 & 3.25 & \\
SDNU & 107 & 3.30 & \\
\hline Q10 QAU & 68 & 3.06 & .334 \\
LDU & 83 & 3.13 & \\
SDNU & 107 & 3.23 & \\
\hline
\end{tabular}

\section{In the aspect of enjoyment}

Table IX below indicates that no any item is statistically correlated with TEM-4 scores. This may suggest that students with the characteristics as Q9, Q12, and Q15 are not significant positive or negative correlated with TEM-4 score.

TABLE IX. CORRELATIONS BETWEEN ENJOYMENT WITH CET-4 SCORES

\begin{tabular}{|c|c|c|}
\hline & & Q9 \\
\hline TEM-4 score & Spearman's rho & -.087 \\
\hline & Sig. (2-tailed) & .163 \\
\hline & $\mathrm{N}$ & 258 \\
\hline
\end{tabular}

Table $\mathrm{X}$ below shows that participants in the three universities only have significant difference in Q9 (I get upset easily when interacting with people from different cultures.) (p $=.040$ ), but not in the rest of the items. This may signify that the less the students "get upset easily when interacting with people from different cultures" the more they achieve. But this does not exist in Items 12 and 15.
TABLE X. THE DIFFERENCE AMONG THE THREE UNIVERSITIES IN ENJOYMENT BY ANOVA

\begin{tabular}{|c|c|c|c|}
\hline & $\mathbf{N}$ & Mean & Sig. \\
\hline Q9 QAU & 68 & 2.43 & .040 \\
LDU & 83 & 2.36 & \\
SDNU & 107 & 2.13 & \\
\hline Q12 QAU & 68 & 2.40 & .903 \\
LDU & 83 & 2.36 & \\
SDNU & 107 & 2.35 & \\
\hline Q15 QAU & 68 & 2.18 & .690 \\
LDU & 83 & 2.14 & \\
SDNU & 107 & 2.07 & \\
\hline
\end{tabular}

\section{E. In the aspect of attentiveness}

Table XI below shows that attentiveness reflected by Q14, Q17, Q19 have no significant correlation with TEM-4 score. This may suggest that those students with the characteristics as Q14, Q17, Q19 reflect, have no significant effect on TEM-4 score.

TABLE XI. CORRELATIONS BETWEEN ATTENTIVENESS WITH CET-4 SCORES

\begin{tabular}{|c|c|c|}
\hline & & Q19 \\
\hline TEM-4 score & Spearman's rho & .038 \\
\hline & Sig. (2-tailed) & .543 \\
\hline & $\mathrm{N}$ & 258 \\
\hline
\end{tabular}

Table XII below shows that students in the three universities have no significant difference in Q14, Q17, and Q19. This may also confirm the result of the above correlation that those students with the characteristics as Q14, Q17, Q10 reflect have no significant effect on TEM-4 score.

TABLE XII. THE DIFFERENCE AMONG THE THREE UNIVERSITIES IN ATTENTIVENESS BY ANOVA

\begin{tabular}{|c|c|c|c|}
\hline & $\mathbf{N}$ & Mean & Sig. \\
\hline Q14 QAU & 68 & 3.44 & .537 \\
LDU & 83 & 3.39 & \\
SDNU & 107 & 3.50 & \\
\hline Q17 QAU & 68 & 3.91 & .984 \\
LDU & 83 & 3.89 & \\
SDNU & 107 & 3.91 & \\
\hline Q19 QAU & 68 & 3.29 & .398 \\
LDU & 83 & 3.35 & \\
SDNU & 107 & 3.20 & \\
\hline
\end{tabular}

\section{CONCLUSION}

The results of the study show that English proficiency has some positive effects on English learners' intercultural sensitivity. It reveals that participants with higher TEM-4 scores acquired the higher intercultural sensitivity than those with lower TEM-4 scores. The correlation and difference can be proved to be statistically significant in the aspects of engagement and respect for cultural differences.

The reasons for the positive correlation are because people are willing to engage in intercultural interaction when they can communicate with people in other cultures fluently in English. And they may learn more knowledge of other cultures in communication. The more cultures they learn, the more respects they would pay to the differences in other cultures. 
However, results also show that there is no significant correlation and difference in the aspects of confidence, enjoyment and attentiveness. The reasons for the results are because all the participants are English major students. They have learned many English courses such as English and American Literature, English Extensive Reading, Brief Introduction to the Western Cultures. All these courses touch upon cultural teaching, which helps to enhance the English learners' intercultural communication competence. Therefore, participants' TEM-4 scores barely have any effects on their confidence, enjoyment and attentiveness in intercultural communication. Besides, students' intercultural sensitivity regarding confidence, enjoyment and attentiveness are more likely associated with their psychology, emotion and motivation.

Practically, the present study may be significant in providing first hand data and analysis of the status quo of the Intercultural sensitivity of Chinese English majors. The findings in the study can provide some food for studies in intercultural training and developing, language and culture acquisition or intercultural study on Chinese English majors.

Although the study has revealed the positive correlation between intercultural sensitivity and English proficiency, it does not make deeper analysis on what factors leading to the correlation and what correlative relations each aspect of intercultural sensitivity has. It is recommended in future research to alleviate this deficiency.

\section{ACKNOWLEDGMENT}

Many thanks are due to Prof. Xiu Xudong who offered meticulous, considerate, insightful and patient supervisions on this article. Appreciation should also go to all participants (students, teachers at Shandong Normal University, Ludong University, Qingdao Agricultural University) for piloting and providing the fieldwork data.

\section{REFERENCES}

[1] Gudykunst, W. B., Hammer, M, R., \& Wiseman, R. L, “An analysis of an integrated approach to cross cultural training," International Journal of Intercultural Relations, 1977.

[2] Chen, G. M., \& Starosta, W. J., "A review of the concept of intercultural sensitivity,” Human Communication, 1997, pp. 1-16.

[3] Chen, G. M. \& Starosta, W. J., "The development and validation of the intercultrural communication sensitivity scale,” Human Communication, 2003, pp: 1-15.

[4] Chen, G. M., Foudations of Intercultural Communication, East China Normal University Press, 2009.

[5] Lustig M, \& Koester J., Intercultural Competence: Interpersonal Communication Across Cultures, $5^{\text {th }}$ Ed, Shanghai: Shanghai Foreign Language Education Press, 2007.

[6] Spitzberg, B. H., \& Changnon, G. Conceptualising Intercultural Competence, In D. Deardorff (ED.), The Sage Handbook of Intercultural Competence, Los Angeles, CA: Sage, 2009.

[7] Chen, G. M., \& Starosta, W. J., "Intercultural communication competence: A synthesis,” Communication Yearbook, vol. 19, 1996, pp: 353-383.

[8] Bronfenbrener, U., Harding, J, \& Gallwey, M., The Measurement of Skill in Social Perception. In McClelland, D. C. (Ed.), Talent and Society. New York: Van Nostrand, 1958.

[9] Bennett, M. J., Towards Ethnorelativism: A development model of intercultural sensitivity. In R. M. Paige (Ed.). Education for the intercultural experience, Yarmouth, ME: Intercultural Press, 1993, pp:2171.

[10] Chen, G. M., \& Starosta, W. J., Foundations of Intercultural Communication, Boston: Allyn \& Bacon, 1998.

[11] Bennett, M. J., Towards Ethnorelativism: A developmental model of intercultural sensitivity, In Paige R M ( Ed.). Cross-cultural Orientation: New Conceptualizations and Applications. New York: University Press of America, 1986, pp: 27-69.

[12] Peng Shiyong, "Intercultural sensitivity: a comparison between English majors and non-English majors," Journal of Ningxia University, Humanities \& Social Science Edition, 2007, PP: 171-176.

[13] Peng Shiyong, "Intercultural communication study in China: status quo, problem and suggestion,” Journal of Hunan University, Humanities and Social Science Edition, 2005, vol. 19, pp: 86-91.

[14] Zhou Xingying, \& Peng Xuemin, "Study on impact of cultural study on intercultural sensitivity, “ Journal of Sichuan College of Education, 2007.

[15] Chen, G. M., \& Starosta, W. J., Communication and Global Society, New York: Peter Lang, 2000. 